ISSN 1518-3483

Licenciado sob uma Licença Creative Commons

\title{
A força da educação na integração de refugiados no Brasil: crianças russas na cidade de Santos (1958-1968)
}

The strength of education in the integration of refugees in Brazil: Russian children in the city of Santos (1958-1968)

Marina Tucunduva Bittencourt Porto Vieira, Fabiano Lourenço de Menezes, Bárbara Higa Silva*

\section{Resumo}

Este artigo baseou-se em uma pesquisa que analisou o Instituto São Vladimir, entre os anos de 1958 a 1968. O Instituto São Vladimir foi uma instituição criada com o propósito de integrar crianças russas que chegaram como refugiadas da China na cidade de Santos. Os internos frequentavam escolas da cidade, onde tinham a educação formal durante um período do dia e a educação informal no local de moradia. O objetivo da instituição era

* Doutora em Educação, e-mail: marinaportovieira@unisantos.br

Doutor em Integração da América Latina, e-mail: fabiano.menezes@unisantos.br Licenciada em História, e-mail: barbara.higa@gmail.com 
inseri-los em uma nova cultura e, simultaneamente, conhecerem e valorizarem a cultura russa. A pesquisa foi qualitativa e com o uso da técnica da história oral coletamos cinco depoimentos: de um ex-diretor, três ex-internos e um frequentador. O estudo examinou as estratégias de educação utilizadas no Instituto São Vladimir para preservar e difundir a cultura russa e a influência que tais estratégias tiveram nas vidas das crianças que frequentaram o instituto. Os resultados indicam que o processo para integrar as crianças refugiadas no Brasil foi um marco para o processo de integração local de refugiados. Concluiu-se que ter passado pelo Instituto deixou marcas importantes na vida das pessoas que o frequentaram e houve um processo de hibridação cultural. Hoje os ex-internos continuam frequentando festividades russas na cidade de São Paulo, onde é possível observar a presença da inter-relação de hábitos russos e brasileiros.

Palavras-chave: Refugiados russos. Integração local. Cidade de Santos. Educação.

\section{Abstract}

This article was based on a research that analyzed the Institute of St. Vladimir, between the years 1958-1968. The Institute of St. Vladimir was an institution created to integrate Russian children coming as refugees from China in the city of Santos. The internees attended local schools, where they had a formal education during the day and informal education in the institute. The aim of the institution was to integrate them in a new culture without losing contact with the Russian culture. The research was qualitative and with the use of oral history technique, we collected five testimonies: from a former director, from three former internees and from one former visitor. The study analyzed the educational strategies employed in the Institute of St. Vladimir to preserve and disseminate Russian culture and how such strategies influenced the children that attended the institute. The results indicate that the process to integrate Russian refugee children in Brazil was a landmark in the process of local integration of refugees. It was concluded that the Institute left important marks in their lives of the internes, especially related to culture hybridization. Today the former children from the institute still attending Russian festivities in the city of São Paulo, where you can observe the interrelation of Russian and Brazilian cultures.

Keywords: Russian refugees. Local integration. City of Santos. Education. 


\section{Introdução}

O porto de Santos tem servido de porta de entrada e saída de migrantes. Pessoas que vão e vem, do Brasil e do resto do mundo, embarcam e desembarcam, carregados de sonhos e desilusões. Alguns são imigrantes que, voluntariamente, deixaram o lugar de origem e vieram movidos pela esperança de uma vida melhor. Outros são refugiados, forçados a deixar o seu lugar de origem por sofrer ou temer a perseguição por motivos de raça, religião, nacionalidade, grupo social ou opinião política ${ }^{1}$.

De acordo com o relatório do Alto Comissariado das Nações Unidas para Refugiados (ACNUR), existem hoje em dia cerca de 21 milhões de refugiados no mundo (ACNUR, 2016). Mais da metade dessa população é originária de três Estados (Síria, Afeganistão e Somália). Por outro lado, os Estados em desenvolvimento são os principais Estados de asilo para a maioria dos refugiados. Entre eles, estão a Turquia, o Paquistão, o Líbano, o Irã, a Etiópia e a Jordânia. Com relação à composição da população refugiada, o ACNUR estima que 51 por cento é composta por crianças abaixo dos dezoito anos de idade. Nessa linha, outro dado do ACNUR mostra que 98.800 mil crianças (a maioria do Afeganistão, da Eritreia, da Síria e da Somália) solicitaram refúgio em 78 Estados desacompanhada dos seus pais.

Do ponto de vista da solução duradoura para os refugiados, o ACNUR reconhece três opções. A primeira é a repatriação voluntária. Nessa opção, o refugiado declarado como tal em um Estado de asilo retorna - desde que não se configure mais a perseguição que motivou a sua saída - para o seu Estado de origem. A integração local. Nessa opção, o refugiado consegue se integrar (do ponto de vista econômico, social e cultural) no Estado de asilo. A última solução é o reassentamento. Nesse

1 Convenção Relativa ao Estatuto dos Refugiados de 1951. Adotada em 28 de julho de 1951 pela Conferência das Nações Unidas de Plenipotenciários sobre o Estatuto dos Refugiados e Apátridas, convocada pela Resolução n. 429 (v) da Assembleia Geral das Nações Unidas, de 14 de dezembro de 1950. Entrou em vigor em 22 de abril de 1954. 
mecanismo, o refugiado, por não poder retornar para o seu Estado de origem e tampouco encontrar os requisitos necessários para a sua integração no (primeiro) Estado de asilo, pode ser reassentado em um segundo Estado, que aceite voluntariamente recebê-lo.

Atualmente, o principal problema dos refugiados é a falta de soluções duradouras em razão de três dificuldades: encontrar soluções para os problemas que originaram a saída forçada dos milhares de refugiados; conseguir a integração local nos Estados de asilo; e a falta de iniciativa dos Estados em oferecer quotas para o reassentamento. Portanto, a maioria dos refugiados permanece em Estados de asilo sem alcançar a integração local tornando-se, então, uma solução duradoura. Este estudo observará o papel da educação como um mecanismo para fortalecer a integração local de refugiados.

De acordo com os dados do Comitê Nacional para Refugiados (CONARE), o Brasil conta com 8.863 mil refugiados (CONARE, 2016). Do perfil dessa população, $18 \%$ tem menos de dezoito anos de idade. Estudos sob a perspectiva da integração local como solução duradoura no Brasil apontam que os refugiados estão no perfil sócio econômico das classes C, D e E (BAENINGER, DOMINGUEZ e AYDOS, 2008). Os refugiados no Brasil também enfrentam dificuldades, como acessar os serviços públicos, em especial, saúde e educação, ingressar em programas sociais, obter trabalho formal etc. (MOREIRA, 2014).

Inicialmente, famílias russas foram forçadas a deixar seu Estado de origem e irem à China em busca de proteção após a Revolução Bolchevique de 1917. Estima-se que mais de 150 mil russos fugiram para a cidade de Harbin (região da Manchúria) (PEAKE, 1939). Por outro lado, ao invés de os refugiados russos encontrarem proteção, eles começaram a sofrer perseguição pelos chineses em razão da Revolução Comunista de 1949 (RIECHERS, 2001). Aproximadamente 2.224 russos, vindos da China, vieram se refugiar no Brasil (BYTSENKO, 2006, p. 12). 
Cortês $^{2}$ (apud BYTSENKO, 2006, p. 34) relata que a vinda de russos para o Brasil já havia ocorrido em outras ocasiões: a primeira imigração, entre os anos de 1887 a 1898, para a província de São Paulo, quando houve o financiamento da imigração para o trabalho na cultura cafeeira. A segunda, no período entre os anos de 1905 a 1914, quando houve a retomada da política de custeio de passagens.

Para que as famílias destas crianças pudessem reestruturar suas vidas no Brasil, era necessário que pudessem trabalhar, porém não havia quem pudesse acolher crianças cuja língua e cultura eram tão diversas.

O Vaticano, tomando ciência deste último deslocamento, e levando em consideração as diferenças culturais, enviou para o Brasil sacerdotes, formados no Colégio Russicum, conhecedores da cultura russa e do rito bizantino-eslavo ${ }^{3}$ para ampará-los. Conforme um dos depoimentos colhidos, estas famílias "Chegavam no Brasil sem nada, qualquer um pode dizer a você, os pais aqui iam procurar emprego, iam procurar onde viver, e esses padres foram os que organizavam, junto com uma organização que ajudava [...]" (ex-diretor).

No final do ano de 1953, a pedido dos jesuítas, os meninos russos começaram a ser recebidos na casa da família Zubarev (em Diadema - SP). No ano seguinte, no dia 14 de março, como o número de meninos havia aumentado muito, as crianças foram transferidas para a cidade de Itu, SP. Foi nesta ocasiãos que se criou um internato, o Instituto São Vladimir, instalado em uma sala da Igreja do Bom Jesus.

O número de meninos foi aumentando e, em 1957, o Instituto foi transferido para o prédio do Mosteiro de São Bento, em Santos, onde funcionou até 1968. O objeto deste relato será a educação destes meninos durante o período em que o Instituto funcionou na cidade de Santos. O prédio do antigo Mosteiro foi escolhido pois estava sem função e tinha dimensões favoráveis, tanto nos ambientes internos como externos.

2 CORTÊS, G. M. Migração e Colonização no Brasil. Rio de Janeiro: Livraria José Olímpio, 1958.

3 Bizantino-eslavo é o rito usado pela Igreja Ortodoxa Russa. 
O Instituto São Vladimir tinha por objetivo oferecer aos internos atividades educacionais, artísticas e culturais características da Rússia e, simultaneamente, adaptá-los ao novo contexto sociocultural em que estavam inseridos.

\section{Metodologia}

Como metodologia foi empregada a história oral, considerando que os documentos textuais, referentes ao Instituto São Vladimir, são escassos e limitados.

Como as entrevistas visavam conhecer o cotidiano do Instituto, os esforços se concentraram em encontrar depoentes que se enquadrassem no quesito de ter tido algum tipo de vínculo com o Instituto São Vladimir, entre os anos de 1958 a 1968.

Os depoentes foram contatados principalmente através do Facebook e de encontros sociais, como o Natal russo, celebrado na Capela Bom Jesus do Horto ${ }^{4}$ no dia 11 de janeiro de 2015, a Festa de São Vladimir (reencontro dos ex-alunos do Instituto São Vladimir) na referida Capela, no dia 12 de julho de 2015, além das Divinas Liturgias ${ }^{5}$ aos domingos. Todos os sujeitos contatados residem no estado de São Paulo, concentrados principalmente na Baixada Santista e na cidade de São Paulo.

No total foram colhidos cinco depoimentos, com os seguintes participantes: o ex-diretor, que foi nomeado como tal em 1968 e dirigiu o Instituto até 1969, o ex-aluno A, que ingressou no Instituto em 1954 e ficou até 1962, o ex-aluno B, que residiu no Instituto entre os anos de 1964 a 1969, o ex-aluno C, que morou no Instituto entre os anos de 1956 a 1968 e um frequentador que, eventualmente, visitava o Instituto, entre os anos de 1960 a 1964. A faixa etária estimada dos depoentes situa-se atualmente entre os 60 e os 80 anos de idade.

4 Igreja Ortodoxa da Anunciação do Patriarcado de Moscou. Localizada na Rua dos Sorocabanos, no 150, bairro Ipiranga, São Paulo - SP.

5 Divina Liturgia: na Igreja Ortodoxa o termo refere-se aos cultos, ou, como se nomeia na Igreja Católica, às Missas. 
As entrevistas semiestruturadas foram orientadas por um roteiro e a história oral, neste estudo, foi empregada como "método".

Como método, a história oral se ergue segundo alternativas que privilegiam os depoimentos como atenção central dos estudos. Trata-se de focalizar as entrevistas como o ponto central e de partida para as análises. Para valorizá-las metodologicamente, os oralistas miram sua atenção, desde o estabelecimento do projeto, nos critérios de obtenção das entrevistas, em seu processamento, na passagem do oral para o escrito e nos resultados públicos. Como método, a história oral reúne em torno das entrevistas o conjunto de procedimentos que devem ser explicitados nos projetos (MEIHY, 2005, p. 49).

O obtido foi uma "coletânea de narrativas", que, de acordo com Paul Thompson:

Uma vez que pode ser que nenhuma delas seja, isoladamente, tão rica ou completa como narrativa única, esse é um modo melhor de apresentar um material de história de vida mais típico. Permite, também, que as narrativas sejam utilizadas muito mais facilmente na construção de uma interpretação histórica mais ampla, agrupando-as - como um todo ou fragmentadas - em torno de temas comuns (THOMPSON, 1992, p. 303).

Os depoimentos não foram interpretados e/ou analisados, visando evitar constatações errôneas e indutivas. A proposta foi descrever - tendo como fonte principal a história oral - a historicidade do Instituto São Vladimir. Thompson afirma que se o estudo da memória expressa que todas as fontes históricas são repletas de subjetividade, a presença viva das vozes subjetivas do passado também nos limitam em nossas interpretações (THOMPSON, 1992, p. 195).

Além do registro oral, foi utilizado material iconográfico, na maioria das fotografias fornecidas pelos próprios entrevistados. Estas foram apresentadas durante as entrevistas, visando favorecer o desenvolvimento das mesmas e estimular a memória dos depoentes. 
Após a realização das entrevistas e suas respectivas transcrições, estas foram contextualizadas através da busca de informações que permitiram compreender melhor os dados obtidos. Em especial, pretendeu-se evidenciar a influência da educação fornecida pelo Instituto São Vladimir nas vidas dos depoentes envolvidos, bem como o seu papel na tentativa da preservação cultural dos imigrantes russos.

\section{A educação no Instituto São Vladimir}

Coerente com seus propósitos, o Instituto São Vladimir, enquanto funcionou na cidade de Santos, procurou oferecer aos meninos de origem russa atividades que os levassem a preservar sua identidade, além de procurar inserí-los na cultura local.

Certeau distingue os conceitos de estratégia e tática. Diz este autor:

Chamo de estratégia o cálculo das relações de forças que se torna possível a partir do momento em que um sujeito de querer e poder é isolável de um ambiente. Ela postula um lugar capaz de ser circunscrito como um próprio e portanto capaz de servir de base a uma gestão de suas relações com uma exterioridade distinta (CERTEAU, 1994, p. 46).

Os responsáveis pelo Instituto, dotados de poder, estabeleceram estratégias visando o controle do Instituto. Por outro lado, como veremos adiante, os internos também tiveram suas táticas.

Lembrando que a arquitetura também educa e, como forma de criar um ambiente compatível com a identidade russa, o prédio cedido pela Ordem de São Bento, sofreu algumas adaptações. Uma delas foi a instalação de uma Capela Ortodoxa, na qual eram celebradas missas no rito bizantino e "todo o dia de noite fazíamos a oração ali a oração da noite, oração da manhã, antes de tomar o café da manhã, a oração da manhã era feita ali, alguns se lembram até das orações que eram cantadas e que na igreja ainda cantamos", relatou o ex-diretor. "Na capela nós cantávamos os cantos gregorianos bizantinos [...]" relatou o ex-aluno B. 
O pátio interno do prédio possuia um jardim e nas quatro paredes que o cercavam foram colocados quadros/fotos de paisagens da Rússia. Em um segundo andar, não mais existente, havia um salão que, segundo um dos depoentes, servia de depósito para o teatro e para a guarda de instrumentos musicais e, segundo outro, de sala de música, lembrando que podem estar se referindo a diferentes períodos. Havia também uma biblioteca que, segundo um dos depoentes, era "uma sala só de livros, do teto até em baixo. [...] Nós tínhamos enciclopédia britânica, nós tínhamos a enciclopédia russa, nós tínhamos tudo, tudo, tudo, tudo..." (ex-aluno C). Completando a ambientação, "havia, no corredor uma vitrola antiga, onde ouviam música russa, muita música russa" disse o ex-diretor.

Os alunos frequentavam escolas da cidade, na qual recebiam a educação formal. Frequentaram colégios religiosos, como o Colégio do Carmo e o Colégio Santista, e também estaduais, o Instituto Escolástica Rosa e o Barnabé. Contou o ex-aluno C: "eu me formei como Técnico de Química no Colégio do Carmo [...] E uma boa metade da turma do colégio, tava no Colégio Santista, dos irmãos maristas".

Dentro do prédio do Mosteiro de São Bento, em que residiam, o idioma oficial era o russo. Havia uma rotina estruturada que, basicamente, consistia em acordar por volta das $6 \mathrm{~h} 00 \mathrm{~m}$. Em seguida os alunos faziam suas orações (em russo) na capela ortodoxa e, na sequência, realizavam a primeira refeição, partindo para suas respectivas instituições educacionais. O transporte dos alunos era feito pelo padre responsável pela administração do Instituto que também fazia as compras para as refeições, preparadas atendendo características russa e brasileira.

Durante o período em que não estavam na escola, o tempo era dividido entre tarefas do colégio e aulas extras do próprio Instituto e entretenimento, constituído por brincadeiras livres, principalmente nos espaços externos que circundavam o prédio. Após a ceia, os alunos iam fazer as lições da escola ou brincar e, por fim, eram recolhidos, faziam suas orações na capela e iam dormir.

Como forma de manter a ordem, os religiosos usavam a punição. Contou um dos depoentes que, caso ocorresse de os alunos não fazerem 
silêncio e fossem dormir no horário proposto e os padres percebessem, eram punidos:

[...] mas quando tinha problema disciplinar era lá que era resolvido [claustro / pátio interno], então às altas horas da noite todo mundo era acordado, ia anda lá e ficava andando, dando voltas pra gastar nossa energia pra conseguir dormir, porque não conseguia dormir (risos), então eles gastavam nossa energia andando lá. E ele ficava lendo a bíblia dele, e nós simplesmente andando em volta, andando, andando (ex-aluno A).

Em horários pré-estabelecidos, os internos tinham aulas que visavam conhecer um pouco de sua ascendência: História e Literatura russa, Dança e Música típicas russas, Idioma russo e Teologia. O ex-diretor contou que os meninos

tinham muitas atividades, tinham dança, que é coisa típica dos russos... tinham literatura, liam muito, tinham artes e ofícios, faziam ícones, arte iconográfica, pintavam, desenhavam, tinha trabalhos de madeira, artesanal. E também música, eles tinham muita música, havia um professor de música que vinha de São Paulo, famoso, desde a China e esse uma vez por semana ia lá. Além disso, tinha a parte religiosa que eles seguiam porque eles moravam lá.

Assim como os meninos russos residiam no Instituto São Vladimir, as meninas que vieram na mesma situação moravam em São Paulo, no Instituto Santa Olga. Eventualmente elas vinham ao Instituto São Vladimir passar o dia, acompanhadas pelas religiosas de São Paulo e então eram feitas apresentações de dança e teatro com a participação das crianças dos dois institutos.

As áreas externas, que contornavam o prédio do antigo Mosteiro, eram espaços de lazer. Nessas áreas havia uma abundância de árvores frutíferas e, defronte da edificação tinha uma quadra, onde se praticava vôlei e basquete. Conta um dos depoentes, o ex-aluno C: 
Mas lá nós fizemos um campinho de futebol, que também servia de campinho de vôlei, e tinha quadra de basquete, e nós fizemos... Foi tudo feito lá. [...] Era um negócio fantástico! Aquilo lá era um pomar, ali tinha tudo de dois, dois abacateiros... Nossa! Mas normalmente é feito assim! Dois mangueiros (sic), dois limoeiros, duas enormes árvores... Aquelas altíssimas que soltam uma espécie de algodãozinho... Paineiras! Duas palmeiras enormes, fantásticas! Olha, aquilo lá foi algo fenomenal!

A oportunidade de conviver com outros meninos russos e de jogar bola com eles aos finais de semana foi o que levou um dos depoentes a frequentar o Instituto, principalmente nos finais de semana, assim como participar das excursões de férias para Itanhaém. Aliás, para dois dos entrevistados, as férias em Itanhaém foram os momentos por eles considerados memoráveis, devido à ausência da costumeira rotina. Contou um dos entrevistados

Nós íamos como alunos, mas tinham muito mais russos que iam pra cidade de Itanhaém passar dez dias numa colônia de férias. Geralmente no mês de janeiro. Lá sim era marcante, ai que não tinha rotina, não tinha escola, não tinha... Era só lazer. Lá era uma convivência com os russos muito interessante, aonde se misturavam muitos pais iam pra lá também, muitos adultos, muitas crianças que não estudavam necessariamente no São Vladimir, mas acabavam se encontrando lá nessa colônia de férias, que era iniciativa dos padres também (ex-aluno B).

Acerca da educação que tiveram oportunidade de receber no Instituto São Vladimir, esse mesmo ex-aluno narrou que:

Eles compraram os melhores professores pra gente, eu tive uma educação que dinheiro não compra, é... Absolutamente de graça, nós tínhamos o top do top, em aula de literatura, em aula de russo e vinha umas senhoras de coreografia russa pra ensinar as coreografias das danças pras pessoas... Eles não tinham pobreza lá, então eles investiram na gente... [...] Acho que é um divisor de águas. Eu faço um retrospecto... [...] Então por exemplo, o domínio da língua russa, de literatura, da história, de lógica, de teologia... [...] Eu 
vou resumir em uma frase: eu, aos 16 anos, discutia a teoria evolucionista de Teilhard de Chardin, que eu acho ele muito superior ao Charles Darwin, que foi um jesuita [...] Eu tive o privilégio de discutir profundamente a teoria evolucionista de Teilhard de Chardin aos 16 anos, acho que eu disse tudo né. [...] Essa foi a grande diferença na minha vida.

Como dito anteriormente, da mesma forma que os jesuítas estabeleceram estratégias como forma de controle, os meninos também tinham suas táticas para burlar as regras. Esses contos, astúcias, artimanhas silenciosas e feitos estão inseridos em ações de táticas que, de acordo com Michel de Certeau (1994, p. 85), "são marcos de uma aprendizagem e maneiras próprias de viver as condições impostas pelo sistema”.

Diferentemente da estratégia, a tática se limita ao terreno que lhe é imposto, "é o movimento 'dentro do campo de visão do inimigo', como dizia von Büllow" (CERTEAU, 1994, p. 100). A tática aproveita "ocasiões" e situações favoráveis, e delas depende, todavia não usufrui de benefícios concretos.

Muitos depoentes relataram várias táticas relativas a situações particulares, o que indica que os ex-alunos não eram absolutamente obedientes nem passivos, mas que concebiam um cotidiano criativo, objetivando desviar da ordem efetiva, horários, regras, determinações, para fins próprios.

Um ex-aluno descreveu casos de escapatórias de grupos de meninos que, após o horário determinado para que todos estivessem dormindo, fugiam para o Porto de Santos, onde, segundo o depoimento, puderam aprender a fumar e a falar o idioma inglês. Conta o ex-aluno B:

E lá eu aprendi grandes coisas, por exemplo, eu aprendi a fumar (risos), aprendi a fumar sim lá, [...] no Porto de Santos, porque a noite a gente pulava o muro, depois que os padres achavam que a gente tava dormindo, descia aquela avenida do Valongo, no cais 2, e iam indo, conversando com os marinheiros de navios turcos, egípcios, gregos, russos, tudo o que você possa imaginar de nacionalidade... E a gente sumia, e conversava e falava, eles pediam... Ah... Como é que chama... O autógrafo do Pelé [...] A gente descobriu como é que o Pelé fazia assinatura e já pegava um cartão, já 
fazia a assinatura e ganhava cigarro (risos)... Que eu falava: "eu vou buscar lá"... Então fazia um rabisco do Pelé, quase idêntico né [...]. Então foi onde eu aprendi inglês, eu falo inglês fluentemente e nunca foi numa escola, eu aprendi no Porto, o Porto foi uma grande escola.

No prédio do Mosteiro, residiam, além dos jesuítas e dos meninos, dois monges beneditinos. Em uma das salas guardavam vinho. Os internos descobriram e um relato ilustra mais uma das artimanhas deles "nós conseguimos surrupiar uma chave da adega deles [dos monges], que eles faziam um vinho chamado 'Beneditino', em Vinhedo, e vinham caixa e mais caixas pra Santos. Mas a gente ajudava os padres a consumir (risos) esse vinho, então eles levaram muito anos pra perceber o desfalque na adega" (ex-aluno B).

No que tange às táticas, um ex-aluno relatou um acontecimento referente a uma ação de resistência de sua parte, que era a não utilização do uniforme escolar do Colégio do Carmo - instituição de ensino a qual ele frequentava - e o pagamento inadequado da mensalidade. Devido a tais indisciplinas, ele foi expulso do Colégio e rematriculado em outro, em virtude do seu favorável histórico escolar.

Evidencia-se que aquela instituição superior (o Colégio do Carmo) exerceu sua posição de poder - a expulsão do aluno - , porém foi lesada por dispensar um estudante empenhado. O Instituto, por outro lado, foi obrigado a aceitar a matrícula do aluno em outra escola, mas quem realmente foi beneficiado com esta situação foi o aluno que, em razão de sua própria competência, conseguiu, por intermédio de um padre (um dos coordenadores do Instituto São Vladimir), ser matriculado no Colégio Monte Serrat, que dispensou a obrigatoriedade do pagamento de qualquer taxa.

Aliás, este ex-aluno não foi o único a queixar-se sobre o memorável uniforme do Colégio do Carmo:

[...] A gente punha uma farda, quando eu estudei no Colégio do Carmo, no Colégio do Carmo... Eu não sei agora, mas na época o Colégio do Carmo era 
estupidamente rígido. Nós tínhamos um uniforme praticamente militar, tinha quepe militar, tinha paletó com os botões todos dourados, a calça tinha uma faixa, era um uniforme militar, cinto militar, tudo militar. E era... O sistema era dos freis carmelitas, era um lugar extremamente rígido, coisa que já foi, era um pouco melhor lá no Santista. Eu fiz o ginásio no Colégio do Carmo, na Ponta da Praia (ex-aluno B).

\section{Considerações finais}

Considera-se que os alunos do Instituto puderam experimentar vivências culturais diversas. Eles frequentaram dois espaços formativos, a escola onde era proporcionada a educação formal (sistema de ensino tradicional) e outro onde tinha a educação não formal (Instituto São Vladimir), além da aprendizagem informal, que ocorria em outros espaços.

Meihy (2005) disserta sobre a multiplicidade de identidades, a qual implica negociações permanentes, requalificações dos pressupostos originais e a reafirmação remota dos pólos identitários, exigindo escolhas. Equivale a um processo de "desidentidade", entendida como a caracterização de espaços identitários que dialogam com a substituição de valores culturais prévios. Evidentemente que grupos imigratórios, expostos a uma outra cultura que os atrai, tendem a viver processos duplos de identificação. A adesão a outro meio, no entanto, não é absoluta nem harmoniosa, pois pede um relacionamento com os pressupostos da cultura original, de maneira a proceder a um diálogo que implica renúncias e escolhas.

Deste modo, o Instituto promoveu ações referentes à cultura russa, sendo esta a cultura primária dos refugiados russos, porém, as relações sociais experienciadas fora do Instituto - escola, passeios - e mesmo dentro - televisão - foram determinantes para a formação do processo circunstancial de "desidentidade", aderindo a multiplicidade de identidades, sobretudo quando os alunos atingiram a maioridade e passaram a ser independentes. Sob tal perspectiva, os sujeitos participantes deste contexto, carregam, de forma relativa e indeterminada, em suas práticas culturais, características de matriz russa e brasileira. 
Considerando as práticas que visavam a preservação da identidade cultural russa e, simultaneamente, a inserção em outra cultura, a brasileira, pode-se considerar que os imigrantes passaram por um processo de hibridação, segundo Néstor Garcia Canclini, antropólogo argentino, que diz: "entendo por hibridação processos socioculturais nos quais estruturas ou práticas discretas, que existiam de forma separada, se combinam para gerar novas estruturas, objetos e práticas" (CANCLINI, 2013, p. XIX). Por mais que tenham sido realizadas várias atividades e ações em prol da tentativa da preservação e promoção da cultura russa, houve um processo de hibridação cultural que permitiu que permanecessem vivendo no Brasil, apesar de manterem alguns hábitos russos na alimentação, religião, idioma, costumes.

A identidade cultural, segundo Meihy (2005), representa a resistência, momentos desafiadores ou critérios de negociação de grupos expostos a situações exóticas em relação ao meio original. A assimilação cultural, vivenciada pelos imigrantes russo-chineses (neste caso, os alunos do Instituto São Vladimir), equivale à múltipla identidade, em concordância com o autor, que afirma que grupos imigratórios expostos à outra cultura tendem a viver processos múltiplos de identificação (MEIHY, 2005, p. 87).

Um questionamento que poderia ser feito, seria com relação ao resultado da educação oferecida pelo Instituto São Vladimir na vida posterior dos meninos que por lá passaram. Por meio dos depoimentos, pelo menos aqueles que foram entrevistados, relatam que tiveram oportunidades de inserção social diferenciada. Conta o ex-aluno $C$

Hoje eu sou regente de corais, eu sou tradutor juramentado de russo/português, eu tenho formação química, trabalhei muito tempo com pesquisas hidrometalurgicas na base química [...] Eu sou músico profissional [...] Desde 1965! Eu passei no exame da ordem dos músicos e tudo mais. Recebi vários prêmios da ordem dos músicos por execução, essas coisas assim... Junto com o grupo Volga, me mandou pra Rússia, defendeu as coisas do Brasil (risos)... Eu cantei músicas com a letra do maior poeta russo, a música de minha 
autoria no Museu do Poeta! [...] Em Moscou! Tudo isso a gente deve justamente ao Instituto São Vladimir, não tenha dúvida.

Outro ex-aluno também faz um relato do que lucrou com a estada no Instituto São Vladimir

Eu passei 20 anos em Brasília, é... E uma das grandes honras... Eu fui um refugiado. E uma das grandes coisas que eu fiz em Brasília foi presidir um Conselho Nacional de Imigração, que cuidava de todos os refugiados do Brasil. [...] Agora eu não pararia lá se esses padres não tivessem me preparado, muito bem preparado. [...] Depois eu fui guindado a altíssimos cargos, sem ser político... Eu era disputado a tapa entre os Ministérios em Brasília, fiz parte do CNPD, que é o Conselho Nacional de Pesquisa e Desenvolvimento, fui consultor de universidades... [...] E eu em 1995 tive o privilégio de ajudar a ser um dos coadjuvantes da negociação brasileira pelo fim da guerra da Bósnia-Herzegovina [...] (ex-aluno B).

Outro depoente que, quando menino, frequentava o Instituto, em seu depoimento afirmou:

Foi um contato com pessoas da minha língua né... Porque a gente é estrangeiro, às vezes sente necessidade de estar junto com pessoas da mesma nacionalidade, da mesma cultura, então pra mim foi bom porque tive o contato, inclusive o meu contato com a cultura russa permaneceu. Então foi uma oportunidade né, de permanecer em contato com a cultura russa, cultura e com a religião [...] Foi uma oportunidade de eu manter vínculos com a comunidade, vínculos religiosos e vínculos culturais... Então foi interessante. [...] Mesmo casado, a gente continua frequentando por conta da Igreja do Horto, então enquanto houve esse movimento a gente, mesmo casado, ainda acabei frequentando, quando havia as festas né, eu frequentava. Então a gente sempre teve o interesse de manter um certo vínculo, então pra mim é interessante esse vínculo com a Igreja do Horto, esse vínculo cultural, até hoje pra mim tem esse sentido (frequentador).

Com relação ao processo vivenciado por estas crianças, internos do Instituto São Vladimir e do Instituto Santa Olga, o Pe. Niko Zuzek fez 
a seguinte apreciação sobre a apresentação folclórica dos alunos e alunas no Festival Infanto-Juvenil que ocorreu no dia 25 de setembro de 1960, no Teatro Municipal de São Paulo

Contudo, nada de estranho há de se observar, pois, a responsabilidade que pesava sobre os jovens artistas, além de ser grande, foi consciente. Eles tinham que afirmar perante seus pais, perante o público em geral, que aprenderam a apreciar os valores de seu povo e, ao mesmo tempo, demonstrar perante o Brasil, que os acolheu com muito carinho, o íntimo da alma russa. [...] além de interesse de caráter pessoal, estava em jogo o começo de um convívio cultural, baseado na explicitação de todo um espírito que deveria transparecer através do espetáculo. A tensão, como por encanto, se desfez ao abritem-se as cortinas do palco. Ao desfilar colorido das mocinhas em belíssima "sarafans", dos mini-"mujiks" de botas vermelhas, sorridentes marinheiros e cossacos acrobatas, explodiram de vibração as cordas íntimas da assembleia presente. A inocência do folclore, o contraste da altivez masculina e a graça feminina, além de provocarem sentimentos de entusiasmo e de ternura, fizeram, ao mesmo tempo, encher todos os espaços do enorme teatro, desde a platéia até as galerias, das mais puras e sinceras lembranças e saudades da mãe-pátria (ZUZEK, 1979, p. 20).

Os resultados obtidos nesta pesquisa fornecem evidências da força da educação para as crianças refugiadas. Hoje a maioria dos refugiados no mundo está sem perspectiva de encontrar uma solução duradoura, seja ela a repatriação voluntária, a integração local ou o reassentamento. Um fato preocupante é que a maioria da população refugiada tem menos de dezoito anos de idade. No Brasil, uma parcela da população refugiada encontra-se nesse perfil. Os esforços dos diversos atores envolvidos no processo para acolher as crianças russas através do Instituto São Vladimir constituem um marco à integração local de refugiados no Brasil. 


\section{Agradecimentos}

Agradecemos imensamente aos senhores que nos revelaram detalhes da história do Instituto São Vladimir.

\section{Referências}

ACNUR, Alto Comissariado das Nações Unidas para Refugiados. Global trends: forced displacement in 2015. Genebra: ACNUR, 2016.

BAENINGER, R.; DOMINGUEZ, J.; AYDOS, M. R. Condições de Vida da População Refugiada no Brasil. In: III Congresso da Associação Latino Americana de População, ALAP. Argentina, 2008.

BYTSENKO, A. Imigração da Rússia para o Brasil no início do século XX: Visões do Paraíso e do Inferno. 134 f. Tese (Mestrado em Letras) - Departamento de Letras Orientais da Faculdade de Filosofia, Letras e Ciências Humanas, Universidade de São Paulo, São Paulo, 2006. Disponível em: <file:///C:/Users/Usuario/ Downloads/TESE_ANASTASSIA_BYTSENKO.pdf>Acesso em: 10 nov. 2016.

CANCLINI, N. G. Cultura Híbridas. São Paulo: EDUSP, 2013.

CERTEAU, M. de. A Invenção do cotidiano. Artes de fazer. Petrópolis: Vozes, 1994. Trad. Ephraim Ferreira Alves.

CONARE. Sistema de refúgio brasileiro: desafios e perspectivas. Brasília: CONARE/ MINISTÉRIO DA JUSTIÇA, 2016.

MEIHY, J. C. S. B. Manual de História Oral. 5a ed. São Paulo: Loyola, 2005.

MOREIRA, J. B. Refugiados no Brasil: reflexões acerca do processo de integração local. Revista Interdisciplinar da Mobilidade Humana, v. 22, n. 43, p. 85-98, 2014.

PEAKE, C. H. Refugees in the Far East. The Annals of the American Academy of Political and Social Science, v. 203, p. 55-62, mai. 1939.

THOMPSON, P. A Voz do Passado: história oral. Rio de Janeiro: Paz e Terra, 1992. 
RIECHERS, M. Fleeing revolution: how white russians, academics, and others found an unlikely path to freedom. Humanities. The magazine of the national endowment for the humanities, mai./abr., 2001. Disponível em: <https://www. neh.gov/humanities/2001/mayjune/feature/fleeing>. Acesso em: 19 out. 2016.

ZUZEK, Nino. Atividade Cultural. Periódico "Instituto São Vladimir - 25 anos", São Paulo, SP, jul. 1979, p. 19-20.

Recebido: 25/10/2016

Received: 10/25/2016

Aprovado: 24/11/2016

Approved: 11/24/2016 
